\title{
Study of Severity of Syndrome-X on Lung Function Impairment in Indian Population
}

\author{
Prema Ram Choudhary ${ }^{1, *}$, Munna Lal Jaipal ${ }^{2}$
}

\section{Prema Ram Choudhary ${ }^{1, *}$, Munna Lal Jaipal ${ }^{2}$}

\author{
'Department of Physiology, Banas \\ Medical College and Research Institute, \\ Palanpur, Gujarat, INDIA. \\ ${ }^{2}$ Department of Pediatrics, Banas \\ Medical College and Research Institute, \\ Palanpur, Gujarat, INDIA.

\section{*Correspondence} \\ Dr. Munna Lal Jaipal, \\ Designate Professor, \\ Department of Pediatrics \\ Banas Medical College \& Research \\ Institute, Palanpur, Gujarat, INDIA. \\ Phone: +919558258818 \\ Email: prema5252@gmail.com
}

\section{History}

- Submission Date: 27-04-2021;

- Review completed: 06-06-2021;

- Accepted Date: 14-06-2021.

DOI : 10.5530/ijcep.2021.8.2.17

Article Available online

http://www.ijcep.org

\section{Copyright}

(c) 2021 Phcog.Net. This is an openaccess article distributed under the terms of the Creative Commons Attribution 4.0 International license.

\begin{abstract}
Background and Aim: Syndrome-X and impaired lung functions both have been associated with an increased jeopardy of coronary heart disease (CHD) in the middle aged Indian population. The aim of present study was to investigate the Severity of Syndrome-X on Lung Function Impairment in Indian Population. Methods: This cross sectional study was done among 200 syndrome-X patients at C. U. Shah Medical College, Gujarat, India for the period of three years from July 2012 to June 2015. They were divided into three groups on basis of presence of numbers of components of Syndrome-X. Syndrome-X was defined, National cholesterol Education Program's-Adult Treatment Panel III Criteria. Anthropometric measurements, blood pressure and lung functions were measured. Fasting blood samples were analyzed to measured glucose, triglyceride and high-density lipoprotein (HDL-c) cholesterol. Statistical analysis was done by SPSS windows version 20.0 software. Results: The prevalence of components in syndrome-X patients was $48.5 \%$ with 3,33.5\% with 4 and $18 \%$ with 5 components of syndrome-X. The lung functions variables (FVC; $P<0.05, F E V 1$; $P<0.001$, FEV3; $P<0.05$, FEFR; $P<0.001$ and FEF25-75\%; $P<0.0001$ ) were significantly decreases in patients having 4 or 5 components of syndrome-X as compared to patients having 3 components. Conclusion: It is concluded from present study that the frequency of components of syndrome-X was significantly associated with lung functions impairment. Therefore, this study suggests that lung function test may be useful as an additional evaluation for the syndrome-X in a clinical practice.

Key words: Syndrome-X, Components of Syndrome-X, Lung Functions, Insulin resistance syndrome, cardiovascular disorders, Metabolic Syndrome.
\end{abstract}

\section{INTRODUCTION}

The Syndrome-X (insulin resistance syndrome or Metabolic Syndrome) is the foremost cause of the community health worldwide from last two decades. It is a group of corporeal conditions and various metabolic anomalies which consist of abdominal obesity, increase blood glucose level in addition to insulin resistance (IR), high blood pressure, dyslipidemia and pro-inflammatory states, generally develops simultaneously so as to enhance an individual's peril for development of diabetes mellitus and cardiovascular abnormalities. $^{[1]}$ Declined Pulmonary function, as evaluated by forced vital capacity (FVC) or forced expiratory volume in one second $\left(\mathrm{FEV}_{1}\right)$ and it is well-known to be related with increased incidence and mortality of cardiovascular disorders. ${ }^{[2]}$ Various hefty prospective research reported that lung function impairment was extrapolative of augmented cardio-vascular morbidity and mortality in nonsmoker population. In addition, declined lung functions have been positively associated with hypertension, diabetes mellitus, Low density lipoproteins cholesterol (LDL-c), insulin resistance, and overall obesity which are main cardiovascular risk factor. Thus syndrome-X (Syn-X) and impaired

lung functions both have been linked with an increased jeopardy of coronary heart disease (CHD) in the middle-aged population. ${ }^{[3,4]}$ The impact, frequency of syndrome-X components on lung function impairment is still uncertain. Despite the fact that scarce data are available on the relationship between lungs functions impairment and components of syndrome- $\mathrm{X}$, even as not a single study still performed in Indian population in best of my knowledge. Therefore, the present study is an effort to investigate the severity of Syndrome-X on lung function impairment in Indian Population.

\section{MATERIALS AND METHODS}

This cross-sectional study was carried out in the Department of physiology at Chimanlal Ujamshibhai Shah Medical College, Gujarat, India for the period of three years (from June 2012 to May 2015). The patients with syndrome-X aged between 25-65 years, were arbitrarily chosen from the outpatient clinic (OPD) and endocrine center, Chimanlal Ujamshibhai Shah Medical College and associate hospital. Total 200 Syndrome-X patients, with mean age $52.34 \pm 8.56$, who satisfied the National

Cite this article: Choudhary PR, Jaipal ML. Study of Severity of Syndrome-X on Lung Function Impairment in Indian Population. Int J Clin Exp Physiol. 2021;8(2):70-3. 
Cholesterol, Education Program, Adult Treatment Panel III (NCEP ATP-III 2001) ${ }^{[5]}$ standard were enrolled in this study. Subsequently, all syndrome-X patients were separated into three groups according to presence of syndrome-X components as per NCEP-ATP-III guideline and observed severity of syndrome-X. Group-I: It comprised of 97 patients (61 male and 36 female) with presence of any three syndrome-X components out of five. Group-II: It comprised of 67 patients (21 male and 46 female) with presence of any four syndrome-X components out of five. Group-III: It comprised of 36 patients ( 7 male and 29 female) with presence of five syndrome-X components. Patients have past records of lung disorders, cancer, Smokers, congestive heart disease and pregnant women, were expelled from study. Anthropometric measurements and systemic blood pressure were taken subsequent to entire physical examination. Systemic arterial Blood pressure (BP) was measured with the help of digital sphygmomanometer above the right arm in sitting position with relaxed. Waist circumference (WC) was measured on naked skin during mid respiration at the narrowest notch between the $10^{\text {th }}$ rib and iliac crest to the close $0.1 \mathrm{~cm}$ while the patient was standing. Informed consent was taken from all the patients earlier to start the present study. The study etiquette was approved by institutional ethics committee.

The syndrome-X was diagnosed as per guideline of the National Cholesterol Education Program's Adult treatment panel-III (NCEP ATPIII) standard when more than three out of five components were present. The components of syndrome-X are following; waist circumference (WC) $>102 \mathrm{~cm}$ in men and $88 \mathrm{~cm}$ in women, blood pressure (BP) $>130 / 85 \mathrm{mmHg}$ or on antihypertensive medications, fasting plasma glucose $(\mathrm{FBG})>110 \mathrm{mg} / \mathrm{dL}$ or on anti-diabetic medications, fasting triglycerides $(\mathrm{TG})>150 \mathrm{mg} / \mathrm{dl}, \mathrm{HDL}-\mathrm{C}<40 \mathrm{mg} / \mathrm{dL}$ in males and $<50$ $\mathrm{mg} / \mathrm{dL}$ in females.

Lung function test was achieved in each participant by help of an automated flow-sensing spirometer (Helios 401' Recorders and Medicare Systems Pvt. Ltd Chandigarh, India) standard on American Thoracic Society/European Respiratory Society, 2005 commendations (ATS/ ERS) ${ }^{[6]}$ with all patients in a sitting position. If at all feasible, minimum three and up to a highest of eight forced expiratory maneuvers were done to meet the American Thoracic Society standards. The predicted value, actual value and the percentage predicted value for the individual was recorded by the spirometer and it is based on height, age, gender and ethnicity of the patients. Variables used in the study were the forced vital capacity (FVC \% Predicted Pre-test), forced expiratory volume in $1 \mathrm{sec}$, (FEV ${ }_{1} \%$ Predicted Pre-test), $\mathrm{FEV}_{1}$-to-FVC \% predicted Pre-test ratio, Mean \% predicted Forced Expiratory Flow during the middle of the FVC (FEF 25\%-75\%). The maximum FVC and $\mathrm{FEV}_{1}$ value of the three or more tests with satisfactory curves was used in the analysis.

Blood samples were taken from all participants after twelve hours of fasting then immediately centrifuged $(2500 \mathrm{rpm})$ for $12 \mathrm{~min}$, the sera were separated from blood samples and frozen at $-8^{\circ} \mathrm{C}$ to $-10^{\circ} \mathrm{C}$ until analysis. Fasting blood glucose (FBG), triglycerides (TG), and high-density lipoprotein cholesterol (HDL-C) levels were estimated by enzymatic producer using marketable existing diagnostic kit on biochemical analyzer.

\section{Statistical Analysis of Data}

Lung function variables of the study participants were expressed in mean \pm SD. Independent Student's $t$ test was used to compare differences in the lung function variables among components of syndrome-X groups. The $P$ value $<0.05$ was considered statistically significant. Statistical analysis was finished by SPSS windows version 21.0 software (Statistical Package of Social Science Inc., Chicago, Illinois).

\section{RESULTS}

All Patients with Syndrome-X were alienated into three groups according to presence of syndrome-X variable or components (NCEP-ATP criteria). Group-I: It comprised of 97 patients (61 male and 36 female) with presence of any three Syndrome-X components out of five. GroupII: It comprised of 67 patients ( 21 male and 46 female) with presence of any four Syndrome-X components out of five. Subgroup-III: It comprised of 36 patients ( 7 male and 29 female) with presence of five Syndrome-X components. The prevalence of numbers of diagnostic components of syndrome-X was display in Table 1 ; it shows that of the 200 patients with syndrome -X, $48.5 \%$ were diagnosed with 3 components, and $33.5 \%$ with 4 components and $18 \%$ with 5 components of Syndrome-X.

\section{Lung Functions Variables between Patients with 3 and 4 Components of Syndrome-X}

Table 2 and Figure 1 illustrate the mean and standard deviation values along with the significance of difference between patients with 3 and 4 components of syndrome-X for variables of lung functions. The mean $(1.88 \pm 0.50)$ forced vital capacity in patients with 4 components of Syndrome-X was lower than mean $(2.03 \pm 0.54)$ in patients with 3 components and this difference was statistically insignificant $(\mathrm{P}>0.05)$. The mean FEV1 (1.39 \pm 0.49$)$ in patients with 4 components of syndrome-X was very significantly $(\mathrm{P}<0.001)$ lower than the mean $(1.65 \pm 0.52)$ in patients with 3 components. The mean $\mathrm{FEV}_{3}$ in group-I and group-II were $(1.99 \pm 0.55)$ and $(1.81 \pm 0.50)$ respectively. The $\mathrm{FEV}_{3}$ mean value was significant $(\mathrm{P}<0.05)$ when compared between two group. The mean value $(3.84 \pm 1.46)$ of FEFR was very significantly $(\mathrm{P}<0.01$ lower in patients with 4 components of syndrome- $X$ when compared to mean value $(4.54 \pm 1.73)$ in patients with 3 syndrome-X variables. There was extremely significant $(\mathrm{P}<0.0001)$ difference between the mean $(1.69 \pm 0.74)$ of FEF25-75\% in

\section{Table 1: Distribution of patients according to presence of syndrome-X} components.

\begin{tabular}{|c|c|c|c|c|}
\hline \multirow{2}{*}{$\begin{array}{l}\text { Numbers of Components of } \\
\text { syndrome-X }\end{array}$} & \multicolumn{3}{|c|}{ Syndrome-X Patients $(n=200)$} & \multirow{2}{*}{$\%$} \\
\hline & Male & Female & Total & \\
\hline Group-I (3 components) & 61 & 36 & 97 & 48.5 \\
\hline Group-II (4 components) & 21 & 46 & 67 & 33.5 \\
\hline Group-III (5 components) & 7 & 29 & 36 & 18 \\
\hline Total & 89 & 111 & 200 & 100 \\
\hline
\end{tabular}

Table 2: Lung functions variables between group-I and group-II of syndrome-X patients.

\begin{tabular}{ccccc} 
Lung functions & $\begin{array}{c}\text { Group-I } \\
(3-S y n-X) \\
(\text { Mean } \pm \text { SD) }\end{array}$ & $\begin{array}{c}\text { Group-II } \\
(4-S y n-X) \\
\text { (Mean } \pm \text { SD) }\end{array}$ & $\begin{array}{c}t- \\
\text { Values }\end{array}$ & P-Values \\
\hline FVC (L) & $2.03 \pm 0.54$ & $1.88 \pm 0.50$ & 1.777 & 0.077 \\
FEV1(L) & $1.65 \pm 0.52$ & $1.39 \pm 0.49$ & 3.232 & 0.001 \\
FEV3 & $1.99 \pm 0.55$ & $1.81 \pm 0.50$ & 2.183 & 0.030 \\
FEFR(Lls) & $4.54 \pm 1.73$ & $3.84 \pm 1.46$ & 2.708 & 0.007 \\
FEF25-75\% (L's) & $2.26 \pm 0.97$ & $1.69 \pm 0.74$ & 4.061 & 0.000 \\
FEV1/FVC (\%) & $81.85 \pm 11.33$ & $80.96 \pm 9.49$ & 0.528 & 0.599 \\
\hline
\end{tabular}

FVC: Force vital capacity; $\mathrm{FEV}_{1}$ : Force expiratory volume in $1 \mathrm{sec}$; $\mathrm{FEV}_{1}$ : Force expiratory volume in 3 sec; FEFR: Force expiratory flow rate; FEF25\%-75\%: Middle of Force Expiratory Flow. 
group-II when compared to mean $(2.26 \pm 0.97)$ in group-I. The mean value $(80.96 \pm 9.49)$ of $\mathrm{FEV} 1 / \mathrm{FVC}$ in patients with 4 components was comparable to mean value $(81.85 \pm 11.33)$ in patients of group-I.

\section{Lung Functions Variables between Patients with 3 and 5 Components of Syndrome-X}

Table 3 demonstrates the mean \pm SD value beside with significance of difference between group-I and group-III for different lung functions variables. The mean forced vital capacity $(1.83 \pm 0.50)$ in patients with 5 components of syndrome- $X$ was insignificantly $(\mathrm{P}>0.05)$ lower when compared to mean value $(2.03 \pm 0.54)$ in patients with 3 components. The mean $(1.28 \pm 0.45)^{\mathrm{FEV}_{1}}$ in patients with 5 components was lower than the mean $(1.65 \pm 0.52)$ in patients with 3 syndrome-x components and this difference was statistically extremely significant $(\mathrm{P}<0.0001)$. The mean $\mathrm{FEV}_{3}$ in patients with 3 and 5 components of syndrome-X was $(1.99 \pm 0.55)$ and $(1.72 \pm 0.51)$ respectively. This difference was statistically very significant $(\mathrm{P}<0.01)$. There was extremely significant $(\mathrm{P}<0.0001)$ difference between mean $(3.31 \pm 1.16)$ of FEFR in patients with 5 components of syndrome-X compared to mean $(4.54 \pm 1.73)$ in patients with 3 components. The mean value $(1.64 \pm 0.63) \mathrm{FEF} 25-75 \%$ in patients with 5 components was highly significant $(\mathrm{P}<0.001)$ lower than mean value $(2.26 \pm 0.97)$ in patients with 3 components of syndrome-X. The mean $\mathrm{FEV}_{1} / \mathrm{FVC}(81.85 \pm 11.33)$ in group-I was comparable with mean value $(80.17 \pm 10.42)$ in group-III.

\section{Lung Functions Variables between Patients with 4 and 5 Components of Syndrome-X}

Table 4 shows the Mean \pm SD value along with significance of difference between group-II and group-III for different lung functions variables. It is observed that the mean differences between all pulmonary function variables in group-II and group-III were statistically insignificant.

\section{DISCUSSION}

The present cross-sectional study observed that lung functions were decreased according to the degree of severity of syndrome-X. We reported that the mean values of lung function variables $\left(\mathrm{FVC}, \mathrm{FEV}_{1}\right.$, $\mathrm{FEV}_{3}, \mathrm{FEFR}$ and $\left.\mathrm{FEF} 25-75 \%\right)$ were significantly $(\mathrm{P}<0.05)$ decreases in patients having 4 or 5 components of syndrome-X as compared to patients having 3 components (3-Syn-X V/s 4-Syn-X; $<<0.05$ and 3 Syn-X $\mathrm{V} / \mathrm{s} 5$ Syn-X; $\mathrm{P}<0.01)$. There was no significant difference was observed between patients having 4 and 5 components of syndrome-X but mean values were insignificant lower in patients having 5 components of

\section{Table 3: Lung functions variables between group-I and group-III of syndrome-X patients.}

$\begin{array}{ccccc}\text { Lung functions } & \begin{array}{c}\text { Group-I } \\ \text { (3-Syn-X) } \\ \text { (Mean } \pm \text { SD) }\end{array} & \begin{array}{c}\text { Group-III(5- } \\ \text { Syn-X) (Mean } \\ \pm \text { SD) }\end{array} & \begin{array}{c}t \text { - } \\ \text { Values }\end{array} & \begin{array}{c}\text { P- } \\ \text { Values }\end{array} \\ \text { FVC(V) } & 2.03 \pm 0.54 & 1.83 \pm 0.50 & 1.882 & .062 \\ \text { FEV1(L) } & 1.65 \pm 0.52 & 1.28 \pm 0.45 & 3.777 & .000 \\ \text { FEV(3) } & 1.99 \pm 0.55 & 1.72 \pm 0.51 & 2.538 & .012 \\ \text { FEFR(Lls) } & 4.54 \pm 1.73 & 3.31 \pm 1.16 & 3.938 & .000 \\ \text { FEF25-75(L's) } & 2.26 \pm 0.97 & 1.64 \pm 0.63 & 3.544 & .001 \\ \text { FEV1/FVC (\%) } & 81.85 \pm 11.33 & 80.17 \pm 10.42 & .775 & .440\end{array}$

FVC: Force vital capacity; FEV : Force expiratory volume in 1 sec; FEV : Force $_{1}$ expiratory volume in $3 \mathrm{sec}$; FEFR: Force expiratory flow rate; FEF25\%-75\%: Middle of Force Expiratory Flow.
Syndrome-X. Our results are in accordance with many previous studies. [7-10]

In a Korean study, the Mean $\pm \mathrm{SD}$ value for $\mathrm{FVC}$ and $\mathrm{FEV}$, according to the number of syndrome- $\mathrm{X}$ components were as follows: Syn- $\mathrm{X}=0$ $(97.6 \pm 12.0 \%, \quad 106.5 \pm 14.5 \%$, respectively), Syn-X=1 $(96.5 \pm 11.4 \%$,
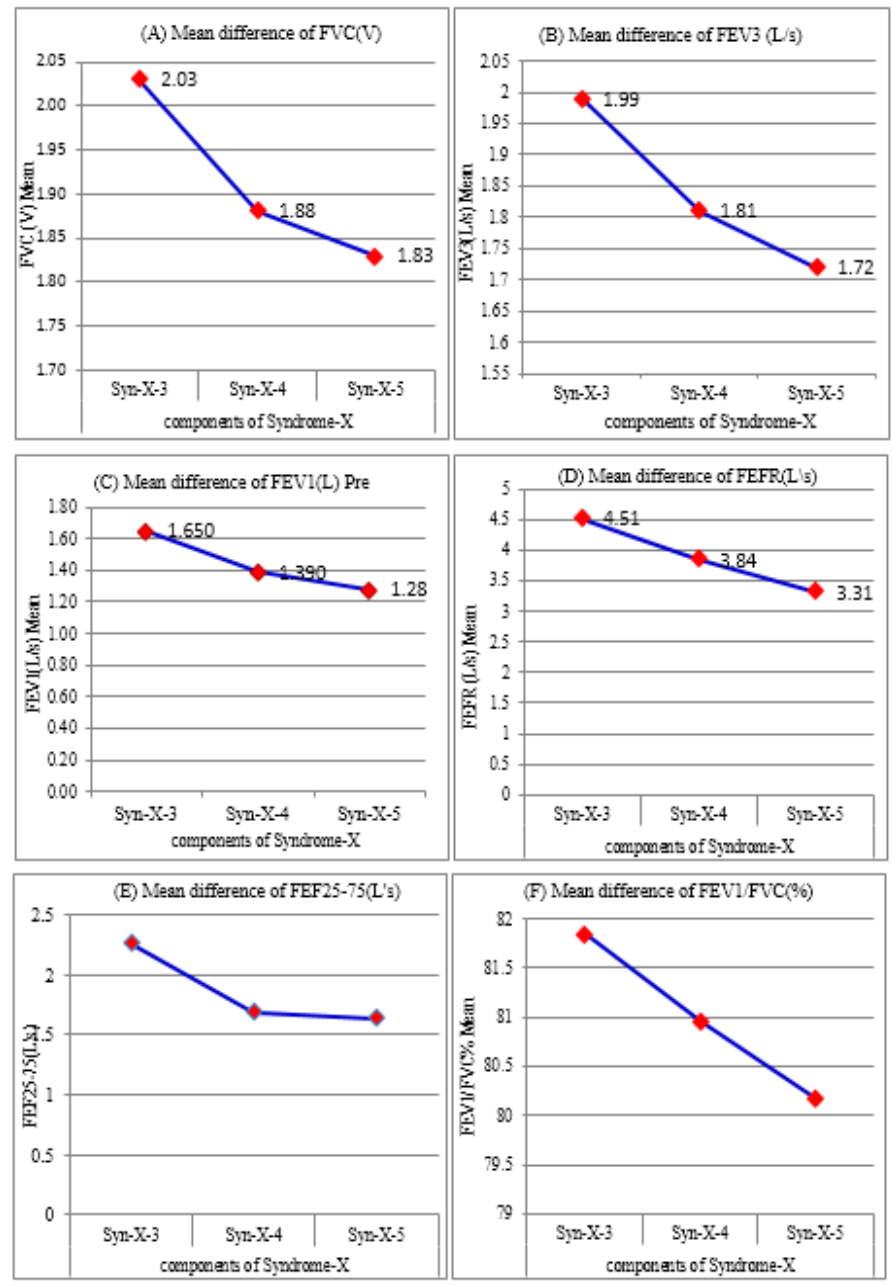

Figure 1: Comparison of pulmonary functions variables between presences of metabolic components.

Table 4: Lung functions variables between group-II and group-III of syndrome-X patients.

$\begin{array}{ccccc}\begin{array}{c}\text { Lung } \\ \text { functions }\end{array} & \begin{array}{c}\text { Group-II } \\ \text { (4-Syn-X) } \\ \text { (Mean } \pm \text { SD) }\end{array} & \begin{array}{c}\text { Group-III } \\ \text { (5-Syn-X) (Mean } \\ \pm \text { SD) }\end{array} & \begin{array}{c}t \text { - } \\ \text { Values }\end{array} & \begin{array}{c}\text { P- } \\ \text { Values }\end{array} \\ \text { FVC(V) } & 1.88 \pm 0.50 & 1.83 \pm 0.50 & .450 & .653 \\ \text { FEV1(L) } & 1.39 \pm 0.49 & 1.28 \pm 0.45 & 1.115 & .267 \\ \text { FEV(3) } & 1.81 \pm 0.50 & 1.72 \pm 0.51 & .803 & .424 \\ \text { FEFR(L/s) } & 3.84 \pm 1.46 & 3.31 \pm 1.16 & 1.877 & .063 \\ \text { FEF25-75(L's) } & 1.69 \pm 0.74 & 1.64 \pm 0.63 & .326 & .745 \\ \text { FEV1/FVC } & 80.96 \pm 9.49 & 80.17 \pm 10.42 & .388 & .699 \\ \text { (\%) } & & & & \end{array}$

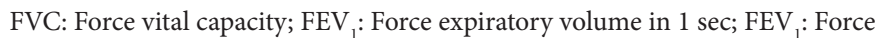
expiratory volume in 3 sec; FEFR: Force expiratory flow rate; FEF25\%-75\%: Middle of Force Expiratory Flow. 
$105.9 \pm 12.9 \%)$, Syn-X $=2 \quad(96.3 \pm 11.3 \%, 105.2 \pm 13.4 \%)$, Syn-X=3 ( $94.3 \pm 12.1 \%, 103.4 \pm 14.6 \%)$, Syn-X=4 (93.4 $\pm 11.9 \%, 104.1 \pm 14.7 \%)$, and Syn-X=5 $(90.7 \pm 12.3 \%, 99.8 \pm 13.9 \%)$. The tendency of FVC and $\mathrm{FEV}_{1}$ to decrease with an increasing number of components of Syndrome-X. Thus, patients having three or more components of syndrome- $\mathrm{x}$ significantly associated with declines in FVC and $\mathrm{FEV}_{1} \cdot{ }^{[10]}$ These observations are in agreement our study. Similarly, another Korean study ${ }^{[8]}$ showed that lung function decreased according to the degree of severity of syndrome-X. In the case of men, FVC and $\mathrm{FEV}_{1}$ decreased as severity of metabolic syndrome increased, while there was no significant relationship found among women, which is in accordance present observations. In a Japanese study, the FVC (\%predicted) values were significantly decreased in smoker and non-smoker across increasing incidence of metabolic components $(\mathrm{P}<0.0001)$. Smoking was correlated with an around $2.7 \%$ turn down in FVC (\% predicted) across number of metabolic components ranges $(\mathrm{P}<0.0001)$. However, having three or more metabolic components were related to a more seriously decreased (around 6.3\%) in FVC (\% predicted), irrespective of smoking condition. Though the $\mathrm{FEV}_{1} / \mathrm{FVC}$ ratio in nonsmokers was significantly decreased across increasing incidence of metabolic components $(\mathrm{P}<0.0001)$, the $\mathrm{FEV}_{1} / \mathrm{FVC}$ ratio in smokers was not significantly changed. The $\mathrm{FEV}_{1} /$ FVC ratio in smokers with number of metabolic components of 0 and 1 was significantly decreased compared with the respective nonsmokers $\left(\mathrm{P}<0.02 ; \mathrm{P}<0.0002\right.$, respectively). ${ }^{[7]}$ In our observation $\mathrm{FEV}_{1} / \mathrm{FVC}$ was not significantly changed when increasing the number of components of syndrome-X. These are in consistent with our study. In the National Health and Nutrition Examination Survey (NHANES-US 2007-2010) it was reported that mean levels of $\mathrm{FEV}_{1}, \mathrm{FEV}_{1} \%$ predicted, $\mathrm{FVC}$, and FVC \% predicted decreased significantly as the number of components of syndrome-x increased ${ }^{[11]}$ which is in accord with our results. Another cross-sectional population based study reported that patients with higher prevalence of components of syndrome-x had lower \% predicted values of FVC and FEV1 $(\mathrm{P}<0.001)$. Impaired lung function was also associated with individual components of syndrome- $\mathrm{x}$, such as waist circumference, hypertension, high TGs, and low high density lipoprotein (HDL) cholesterol $(\mathrm{P}<0.05)$. These results advise that an increased numbers of metabolic components (Syn-X $>3$ ) is sturdily associated with lower $\mathrm{FVC}$ and $\mathrm{FEV1}^{[9]}$ these findings are in conformity with observation of our study.

\section{Limitations of the Study}

There is limitation of the study, this is a cross-sectional design, and further longitudinal studies are needed to investigate the interactions between lung function and components of Syndrome-X with prospect cardiovascular disorders.

\section{CONCLUSION}

The lung functions were declined according to the degree of severity of syndrome $-\mathrm{X}$. The mean values of lung functions variables (FVC, FEV $\mathrm{FEV}_{3}, \mathrm{FEFR}$ and FEF25-75\%) were significantly decreases in patients having 4 or 5 components of syndrome-X as compared to patients having 3 components. Hence, the frequency of components of syndrome-X was significantly associated with lung function impairment. Present study suggests that lung function test may be useful as an additional evaluation for the syndrome-X in a clinical practice.

\section{ACKNOWLEDGEMENTS}

The interrogators would like to concede all the participants of the present study and we are also thankful to Dr. R. D. Jani, Professor and Head, Department of Physiology, C. U. Shah Medical College, Gujarat, India, for his moral support and encouragement for the present study.

\section{CONFLICT OF INTEREST}

The authors declare no conflict of interest.

\section{ABBREVIATIONS}

CHD: Coronary Heart Disease; HDL-c: High-Density Lipoprotein; FVC: Forced Vital Capacity; FEV $_{1}$ : Forced Expiratory Volume In One Second; LDL-c: Low Density Lipoproteins Cholesterol; Syn-X: Syndrome-X; NCEP ATP-III: National Cholesterol, Education Program, Adult Treatment Panel III; WC: Waist Circumference.

\section{REFERENCES}

1. Pandey S, Baral N, Majhi S, Acharya P, Karki P, Shrestha S, Das BK, Chandra L. Prevalence of the metabolic syndrome in acute myocardial infarction and its impact on hospital outcomes. Int J Diabetes Dev Ctries. 2009;29(2):52-5. doi: 10.4103/0973-3930.53120, PMID 20142868

2. Lim SY, Rhee EJ, Sung KC. Metabolic syndrome, insulin resistance and systemic inflammation as risk factors for reduced lung function in Korean nonsmoking males. J Korean Med Sci. 2010:25(10):1480-6. doi: 10.3346/ jkms.2010.25.10.1480, PMID 20890430.

3. Leone N, Courbon D, Thomas F, Bean K, Jégo B, Leynaert B, Guize L, Zureik M. Lung function impairment and metabolic syndrome: the critical role of abdominal obesity. Am J Respir Crit Care Med. 2009;179(6):509-16. doi: 10.1164/ rccm.200807-11950C, PMID 19136371.

4. Choudhary PR. Study of thyroid and pulmonary function in metabolic syndrome: materials and methods and results. Ph.D. Available from: http://hdl. handle.net/10603/149315 [dissertation]. Gujarat, India: Saurashtra University: Rajkot; 2016.

5. Executive summary of the third report of the national cholesterol education program (NCEP) expert panel on detection, evaluation, and treatment of high blood cholesterol in adults (Adult Treatment Panel III). JAMA. 2001;285:24-86.

6. Miller MR, Hankinson J, Brusasco V, Burgos F, Casaburi R, Coates A, Crapo R, Enright $P$, van der Grinten CP, Gustafsson P, Jensen R, Johnson DC, Maclntyre N, McKay R, Navajas D, Pedersen OF, Pellegrino R, Viegi G, Wanger J, ATS/ERS Task Force. Standardisation of spirometry. Eur Respir J. 2005:26(2):319-38. doi: 10.1183/09031936.05.00034805, PMID 16055882.

7. Nakajima K, KubouchiY, Muneyuki T, Ebata M, Eguchi S, Munakata H. A possible association between suspected restrictive pattern as assessed by ordinary pulmonary function test and the metabolic syndrome. Chest. 2008;134(4):712-8. doi: 10.1378/chest.07-3003, PMID 18625672.

8. Bae MS, Han JH, Kim JH, Kim YJ, Lee KJ, Kwon KY. The Relationship be tween metabolic syndrome and pulmonary function. Korean J Fam Med. 2012;33(2):70-8. doi: 10.4082/kjfm.2012.33.2.70, PMID 22745890.

9. Chen WL, Wang CC, Wu LW, Kao TW, Chan JYH, Chen YJ, Yang YH, Chang YW, Peng TC. Relationship between lung function and metabolic syndrome. PLOS ONE. 2014;9(10):e108989. doi: 10.1371/journal.pone.0108989, PMID 25299452.

10. Kim SK, Hur KY, Choi YH, Kim SW, Chung JH, Kim HK, Lee MK, Min YK, Kim $\mathrm{KW}, \mathrm{Kim} \mathrm{JH}$. The relationship between lung function and metabolic syndrome in obese and non-obese Korean adult males. Korean Diabetes J. 2010;34(4):25360. doi: 10.4093/kdj.2010.34.4.253, PMID 20835343.

11. Ford ES, Cunningham TJ, Mercado Cl. Lung function and metabolic syndrome: findings of National Health and Nutrition Examination survey 2007-2010. J Diabetes. 2014;6(6):603-13. doi: 10.1111/1753-0407.12136, PMID 26677470. 